\title{
Iron Deficiency in Infancy Predicts Altered Serum Prolactin Response 10 Years Later
}

\author{
BARBARA FELT, ELIAS JIMENEZ, JULIA SMITH, AGUSTIN CALATRONI, NIKO KACIROTI, GLORIA WHEATCROFT, AND \\ BETSY LOZOFF
}

\author{
Center for Human Growth and Development [B.F., J.S., A.C., N.K., G.W., B.L.], Department of Pediatrics and Communicable Diseases \\ [B.F., B.L.], University of Michigan, Ann Arbor, MI 48109; Hospital Nacional de Niños [E.J.], San Jose, Costa Rica
}

\begin{abstract}
Serum prolactin may reflect CNS dopaminergic function. Because iron deficiency (ID) alters brain dopamine in rats, serum prolactin levels were previously investigated in infants with varied iron status. High serum prolactin levels correlated with behaviors typical of chronic ID. The objective of this study was to determine the effect of infant iron status on serum prolactin levels after a stressor in early adolescence. One hundred fifty-nine of 191 children enrolled in infancy (chronic ID, $n=46$; good iron comparison group, $n=113$ ) had serum prolactin measurements after catheter placement at 11-14 y of age. Serum prolactin levels were compared by sex, pubertal status and infant iron status and the pattern of change over time was compared by infant iron status controlling for pubertal stage and background factors. Males and less mature adolescents had lower serum prolactin concentrations than females and more mature adolescents. Controlling for these factors, the serum prolactin response pattern differed significantly by infant iron status. Serum prolactin declined earlier for the chronic ID group. In conclusion, an altered serum prolactin response pattern was observed $10 \mathrm{y}$ after chronic ID in infancy and may suggest a long-lasting effect of ID on the regulation of prolactin. (Pediatr Res 60: 513-517, 2006)
\end{abstract}

$\mathrm{T}$ The hormone prolactin has typically been associated with processes of lactation. However, prolactin has also been shown to have a broad range of functions (1-3). An area of particular attention has been prolactin as a stress-response hormone. Studies in biologic psychiatry have documented a rise in serum prolactin levels after physical and psychological stress (4-8).

Serum prolactin has been considered a peripheral indicator of central dopaminergic function, because the neurotransmitter dopamine provides the primary tonic inhibitory influence on prolactin release from the anterior pituitary $(9,10)$. Increased dopamine release inhibits prolactin secretion, as can reduced dopamine reuptake through decreased dopamine transporter (DAT) number or function. Among the family of dopamine receptors, $\mathrm{D}_{2}$ is the primary one associated with the inhibition of prolactin release (9). A complex system has been

Received January 10, 2006; accepted June 11, 2006.

Correspondence: Barbara Felt, M.D., University of Michigan, 300 NIB, Room 1000SW, 300 North Ingalls Street, Ann Arbor, MI 48109-0406; e-mail: truefelt @umich.edu

This study was supported by NIH HD36106 and a MERIT Award to B. Lozoff, R37HD31606.

DOI: 10.1203/01.PDR.0000242848.45999.7b demonstrated to regulate prolactin and includes other neurotransmitter systems (e.g., serotonin) $(10,11)$.

We became interested in prolactin in the course of research on iron deficiency, a common nutritional problem that may affect as many as half of the world's infants (12). Of the neurotransmitter systems shown to be altered by iron deficiency in animal studies, dopamine has been studied the most. There is substantial evidence that several aspects of dopaminergic function are altered by iron deficiency $(13,14)$. Early studies showed that iron deficient rats had reduced $\mathrm{D}_{2}$ receptor number and function in the striatum and a behavioral profile similar to that observed with the use of dopamine receptor blocking agents (15). As predicted by these changes, serum prolactin levels and liver prolactin-binding sites were increased in iron deficient rats $(16,17)$. Recent animal studies have suggested more complex dopamine system alterations, including dopamine transporter down-regulation and increased extracellular dopamine levels in the striatum (13).

We previously explored the question of dopaminergic alterations in human iron deficiency by assessing serum prolactin levels in 12- to 23-mo-old infants who participated in a study of the effects of iron deficiency anemia on behavior and development $(7,18)$. Serum was available from the blood obtained for iron status measures before and after three months of iron treatment. Developmental testing preceded venipuncture at both time points. Therefore, serum prolactin levels may have reflected the infant's response to both events. We did not find a significant relationship between infant iron status and serum prolactin levels in that study. However, we found that a high serum prolactin level was associated with the behavioral profile of infants with iron deficiency anemia wary and hesitant behavior during developmental testing. In addition, serum prolactin levels (high or normal) were surprisingly stable over the two assessments.

In the present study, we obtained serum prolactin levels in these same children in early adolescence. While the heightened serum prolactin levels in infancy were related to the wary

Abbreviations: ID, iron deficiency; TIDA, tuberoinfundibular dopminergic neurons. 
Table 1. Subject characteristics and sample collection times by infant iron status

\begin{tabular}{lccc}
\hline & $\begin{array}{c}\text { Chronic Iron } \\
\text { Deficiency Group } \\
(n=46)\end{array}$ & $\begin{array}{c}\text { Comparison } \\
\text { Group } \\
(n=113)\end{array}$ & $57(50 \%)$ \\
& $13(28 \%)$ & $12.4(0.6)$ & $<0.02$ \\
Gender (female)* & $12.1(0.6)$ & $34(30 \%)$ \\
Age (years)** & & $45(40 \%)$ \\
Pubertal development* & $23(50 \%)$ & $34(30 \%)$ & 0.01 \\
Less mature (Tanner I) & $18(39 \%)$ & 0 & 0.01 \\
Intermediate mature (Tanner II-III) & $5(11 \%)$ & $15.6(6.3)$ \\
More mature (Tanner IV-V) & & $30.7(7.1)$ \\
Time of serum samples (min)** & 0 & $52.6(10.3)$ \\
First sample & $15.8(6.6)$ & 0.84 \\
Second sample & $30.2(7.2)$ & 0.74 \\
Third sample & $52.6(9.8)$ & 0.97 \\
Fourth sample & & \\
\hline
\end{tabular}

* Number of participants (percent within infant iron status group).

** Mean (SD).

and hesitant behavioral profile typical of infants with chronic iron deficiency and not iron status per se (5), we believed that a relationship between iron status and altered serum prolactin remained possible. One reason was that affective differences such as wary and hesitant behavior have been observed in every human study of iron deficiency that included such measures in infancy (14). In addition, animal studies have consistently documented dopaminergic alterations with iron deficiency anemia and have documented hesitant behavior after early iron deficiency as well $(13,14,19)$. Based on the association of elevated serum prolactin with the behavioral profile typical of iron deficiency in infancy and the information available from animal studies, we predicted that having chronic iron deficiency in infancy would be associated with elevated serum prolactin levels after a stressor in early adolescence.

\section{METHODS AND MATERIALS}

Subjects. The original cohort consisted of 191 healthy, full-term infants who were enrolled at 12-23 mo of age (between 1983 and 1985) for a study of the behavioral and developmental effects of iron deficiency (18). In infancy, the children resided in a peri-urban, lower-middle-class community in Costa Rica. Infant iron status ranged from moderate iron deficiency anemia to iron sufficiency. Moderate anemia was defined as $\mathrm{Hb} \leq 100 \mathrm{~g} / \mathrm{L}$ and mild anemia was defined as $\mathrm{Hb}$ 101-105 g/L. Iron deficiency was defined as serum ferritin $\leq 12 \mu \mathrm{g} / \mathrm{L}$, and either erythrocyte protoporphyrin $>100 \mu \mathrm{g} / \mathrm{dL}$ packed red blood cells or transferrin saturation $\leq 10 \%$. Iron sufficiency was defined as $\mathrm{Hb} \geq 120 \mathrm{~g} / \mathrm{L}$ and no abnormal iron measures. Infants with $\mathrm{Hb}<$ $120 \mathrm{~g} / \mathrm{L}$ and any degree of iron deficiency (defined above) were given either IM iron (calculated to increase $\mathrm{Hb}$ to $125 \mathrm{~g} / \mathrm{L}$ ), or two daily oral doses of ferrous sulfate ( $3 \mathrm{mg} / \mathrm{kg}$, one dose by project personnel) for a period of three months. Infants who had $\mathrm{Hb} \geq 120 \mathrm{~g} / \mathrm{L}$ and were either iron deficient or iron depleted (serum ferritin $<12 \mu \mathrm{g} / \mathrm{L}$ being the only abnormality) also received the oral iron treatment.

All infants with moderate iron deficiency anemia corrected their anemia with 3 mo of iron treatment. However, $64 \%$ of the infants with moderate IDA still had altered iron status measures after iron treatment (e.g., erythrocyte protoporphyrin $>100 \mu \mathrm{g} / \mathrm{dL}$ packed red blood cells or transferrin saturation $\leq 10 \%$ ). In addition, 17 infants with hemoglobins $>100 \mathrm{~g} / \mathrm{L}$ also had altered iron status measures after iron treatment. Previous analyses have shown that the severity of iron deficiency and response to iron treatment combined are related to CNS outcomes. The entire group of subjects who had moderate iron deficiency anemia in infancy and those who had higher $\mathrm{Hb}$ levels but persisting abnormalities of iron status measures after iron treatment were similar in having poorer long-term behavioral and developmental outcomes $(20,21)$. Both groups of infants had evidence of chronic iron deficiency. Infants with moderate IDA had chronic, severe iron deficiency since anemia is a late manifestation of iron deficiency. The infants who had persisting alterations of iron measures had lower hemoglobins and higher erythrocyte protoporphyrin levels at study entry than those infants whose iron measures completely responded to iron treatment. It is important to note that unmodified cow milk was typically introduced in the first few months of life in this population and that subjects were identified as ID at $12-23 \mathrm{mo}$ in the original study. Thus, the iron deficiency was likely to have been chronic. Previous studies have compared the children with evidence of chronic ID in infancy to children who had good iron status in infancy. The good iron status comparison group consisted of infants who were iron sufficient (as described above) at study entry and/or after iron treatment (other than those with moderate IDA) $(20,21)$. The present study uses the same grouping approach.

Of the original infant cohort, 167 (87\%) participated in a re-evaluation of behavioral and developmental status in early adolescence (11 to $14 \mathrm{y}$ of age) between 1994 and 1995 (21). Serum samples for prolactin were available for 159 of these children. The average age at follow up was $12.3 \pm 0.7 \mathrm{y}$ (range 10.9-13.7 y). There were 70 females and 89 males. Iron status during infancy did not differ significantly for children who participated in this follow-up and those who did not. The project pediatrician obtained signed informed consent from parents and assent from the child. The study protocol was approved by the Institutional Review Boards of the University of Michigan, the Hospital Nacional de Ninos, Costa Rica, and the Office of Protection from Research Risks, National Institutes of Health, Bethesda, MD.

Procedures. Sequential blood samples for prolactin levels were collected in conjunction with a venipuncture to determine iron status in early adolescence. To facilitate repeated blood sampling, an angio-catheter was placed at venipuncture by the project pediatrician who was blind to infant iron status group. Venipuncture and catheter placement occurred between 7:30 and 8:00 $\mathrm{h}$ to minimize variation of serum iron and prolactin levels related to normal diurnal patterns $(22,23)$. The timing of the subsequent samples was guided by the physiology of serum prolactin response to stress. Previous studies in adults have documented an increase in serum prolactin levels within 5-10 min of a stressful event, a peak between $20-30 \mathrm{~min}$, then a decline by $45-60 \mathrm{~min}$ (24). We collected the first sample at venipuncture for catheter placement (the stressor), and sequential samples were planned at $15 \mathrm{~min}, 30 \mathrm{~min}$, and $45 \mathrm{~min}$ thereafter. Between the initial and second samples, all children had a complete physical examination that included an assessment of pubertal stage by standard protocol (25). After the second sample, the children had a break during which they rested, read and had a snack. The children had no other activities between the third and fourth samples. All blood samples for prolactin measurement were immediately centrifuged and the sera separated. Sera were stored at $-20^{\circ} \mathrm{C}$ until assay in duplicate for prolactin concentration (mIU/L) using standard double-antibody RIA kits from ICN Pharmaceuticals, Costa Mesa, California. The assays were completed within 3-4 y of collection. Inter-assay variability was $15 \%$ and the intra-assay variability was $13 \%$.

Our overall measure of pubertal development was pubic hair Tanner stage (1-5). This measure correlated highly with all other ratings of pubertal development (axillary hair, breast or genital development, and menstruation status (all values $r>0.70$ )), and thus, could be applied to both boys and girls. Children were categorized as follows: Tanner stage 1-less mature; Tanner stage 2 and 3 -intermediate mature; and Tanner stage 4 and 5-more mature.

Statistical analysis. The children in the chronic ID group $(n=46)$ were compared with the children who had had good iron status in infancy (the comparison group, $n=113$ ) for age, sex, pubertal development, time of serum prolactin samples, and serum prolactin concentrations using $t$-test for 
Table 2. Serum prolactin concentrations at each sample time by sex

\begin{tabular}{cccc}
\hline Sample & $\begin{array}{c}\text { Female } \\
(n=70)\end{array}$ & $\begin{array}{c}\text { Male } \\
(n=89)\end{array}$ & $p$-value \\
\hline 1 & $391.2(194.5)$ & $331.1(177.6)$ & 0.04 \\
2 & $366.3(202.1)$ & $294.6(166.1)$ & 0.02 \\
3 & $323.0(169.2)$ & $256.0(131.6)$ & 0.01 \\
4 & $294.9(147.7)$ & $229.3(108.1)$ & $<0.01$ \\
\hline
\end{tabular}

Serum prolactin concentrations (mIU/L) at each sample time $(0,15,30,50$ minutes) after venipuncture and catheter placement. Participants are compared by Student's $t$ - test according to sex. Values are expressed as mean (SD).

continuous and normally distributed variables, the Mantel-Haenzael $\chi^{2}$ test for ordered categorical variables, and the Fisher's exact test for dichotomous variables. Serum prolactin levels at each time point were then compared by infant iron status controlling for propensity score, pubertal status and first serum sample prolactin concentration using linear mixed models. We used a propensity score to reduce bias due to group differences in background characteristics and other factors. Propensity scores have been increasingly used in epidemiologic and medical research as an index of the risk (propensity) for the condition of interest (26). The propensity score, consisting of relevant risk factors, is used as a control variable in analyses of outcome. In this study, the condition of interest was iron status in infancy (chronic ID versus the comparison, good iron status group). Based on our previous work, factors that could influence the probability of iron status group were included in the propensity score using multivariate logistic regression. The factors included sex, birth weight, infant feeding history, age at initial enrollment, mother's IQ, socioeconomic status, family structure, and quality of the home environment. The area under the receiver operating characteristic curve (c-statistic) for the propensity score model in this study was 0.84 , indicating excellent discrimination between iron status groups. The propensity score was divided into quintiles and incorporated as a stratified control variable. A linear mixed effects model growth curve analysis was used to account for correlations among observations due to sequential measurements taken on the same individual. The initial level of prolactin after a stressor affects the range of the response curve thereafter (e.g., lower initial levels constrain the amount of possible decline) (27). Therefore, this was controlled in this analysis. We assumed a spatial autocorrelation structure for the covariance matrix where the strength of the correlation between observations was a function of the time interval between measurements. Separate covariance structures were estimated for the chronic ID and good iron status groups due to unequal variances. All statistical tests were two-tailed with alpha levels set at 0.05 . Statistical analyses were conducted using SAS Version 9.1 (28).

\section{RESULTS}

In early adolescence, no child was anemic and only $2 \%$ ( $n$ = 3) had biochemical evidence of iron deficiency (21). The characteristics of the children who had chronic ID in infancy

Table 3. Serum prolactin concentrations by pubertal status

\begin{tabular}{|c|c|c|c|c|}
\hline \multirow[b]{2}{*}{ Sample } & \multicolumn{4}{|c|}{ Pubertal Development } \\
\hline & $\begin{array}{l}\text { Less Mature } \\
\quad(n=57)\end{array}$ & $\begin{array}{c}\text { Intermediate } \\
\text { Mature } \\
(n=63)\end{array}$ & $\begin{array}{l}\text { More Mature } \\
\quad(n=39)\end{array}$ & $p$-value \\
\hline 1 & $319.1(163.7)^{*}$ & $351.3(193.4)^{* *}$ & 428.1 (196.7) & 0.02 \\
\hline 2 & $296.1(167.7)^{*}$ & $317.2(199.8)$ & $383.1(180.6)$ & 0.07 \\
\hline 3 & $255.6(130.1)^{*}$ & $285.9(175.0)$ & 328.1 (138.7) & $<0.01$ \\
\hline 4 & $227.1(104.5)^{*}$ & $244.9(117.1)^{* *}$ & 323.7 (161.1) & $<0.01$ \\
\hline
\end{tabular}

Serum prolactin concentrations (mIU/L) at each sample time $(0,15,30,50$ minutes) after venipuncture and catheter placement. Participants are compared by Student's $t$-test according to pubertal status and values are expressed as mean $(\mathrm{SD})$.

Pubertal Development (Pubic Hair): Tanner stage I, less mature; Tanner stage II-III, intermediately mature; Tanner stage IV-V, more mature.

Pair-wise comparisons $p<0.05$ : * Less mature versus more mature;

** Intermediate mature versus more mature.
Table 4. Unadjusted and adjusted serum prolactin levels by infant iron status group

\begin{tabular}{cllcc}
\hline Sample & Value & $\begin{array}{c}\text { Chronic ID } \\
\text { Group }\end{array}$ & $\begin{array}{c}\text { Comparison } \\
\text { Group }\end{array}$ & $p$-value \\
\hline \multirow{2}{*}{1} & unadjusted & $332.0(155.5)$ & $368.3(198.3)$ & 0.27 \\
2 & unadjusted & $281.8(139.8)$ & $343.8(198.9)$ & 0.03 \\
& adjusted & $312.3(97.39)$ & $348.8(133.3)$ & 0.08 \\
\multirow{2}{*}{3} & unadjusted & $257.6(124.5)$ & $295.8(161.1)$ & 0.16 \\
& adjusted & $293.4(97.00)$ & $297.5(133.9)$ & 0.84 \\
4 & unadjusted & $228.9(119.0)$ & $269.2(133.5)$ & 0.08 \\
& adjusted & $265.9(96.8)$ & $271.7(133.6)$ & 0.78 \\
\hline
\end{tabular}

Unadjusted and adjusted serum prolactin concentrations (mIU/L) at each sample time: 1, at venipuncture and catheter placement; 2, 15 minutes; 3, 30 minutes; 4, 50 minutes after venipuncture and catheter placement. Values are expressed as mean (SD). Unadjusted values are compared by Student's $t$-test according to infant iron status group. Adjusted values are compared by infant iron status group controlling for propensity score, pubertal stage, and the first prolactin sample concentration.

and those who had good iron status before and/or after iron therapy (comparison group) are described in Table 1. There were significantly more males in the chronic ID group and, at the time of assessment, these adolescents were less mature than the comparison group. The actual times of the serum prolactin samples were recorded and found to vary somewhat by individual. However, there was no significant difference for the mean sample times when compared by iron-status group (Table 1).

Serum prolactin levels were compared by sex and pubertal status. In this early adolescent period, males had significantly lower serum prolactin levels than females at each sample time (Table 2). In addition, the less mature adolescents had significantly lower serum prolactin levels at each sample time than those who were more mature (Table 3 ).

Comparing serum prolactin concentrations at each time point by infant iron status, the chronic ID group had significantly lower levels at $15 \mathrm{~min}$ after venipuncture (unadjusted values, Table 4). After controlling for propensity score, pubertal status and the first prolactin sample concentration in the linear effects model, group differences were not significant (adjusted values, Table 4).

The change in serum prolactin between samples $2(15 \mathrm{~min})$ and 3 (30 $\mathrm{min})$, and between samples 3 and 4 (50 $\mathrm{min})$ were compared within and between infant iron status groups using the linear effects model (Table 5). The pattern of serum prolactin response differed for chronic ID versus the good iron status comparison group. The adolescents that had chronic ID in infancy had significantly less decline between 15 and 30 min than the good iron status comparison group. The iron status groups did not differ for amount of serum prolactin change between 30 to $50 \mathrm{~min}$ after venipuncture.

\section{DISCUSSION}

This follow-up of early adolescents who had participated in a study of iron deficiency in infancy provided a unique opportunity to assess long-term alterations in the response of serum prolactin to stress in relation to infant iron status. Based on the association between high serum prolactin levels and the behavioral profile of iron deficiency in infancy and the effects 
Table 5. Change in serum prolactin concentrations by infant iron status group

\begin{tabular}{|c|c|c|c|c|}
\hline \multirow{2}{*}{$\begin{array}{l}\text { Iron Status } \\
\text { Group }\end{array}$} & \multicolumn{4}{|c|}{$\begin{array}{l}\text { Mean prolactin } \\
\text { change between } \\
\text { times } 2-3 \text { and } 3-4\end{array}$} \\
\hline & Sample 2-3 & $p$-value* & Sample 3-4 & $p$-value* \\
\hline Chronic ID group & $18.8(8.9)$ & 0.04 & $27.5(10.6)$ & $<0.01$ \\
\hline Comparison group & $51.3(8.6)$ & $<0.01$ & $25.8(9.9)$ & $<0.01$ \\
\hline$p$-value** & $<0.01$ & & 0.91 & \\
\hline
\end{tabular}

Mean difference for adjusted serum prolactin concentrations controlling for propensity score, pubertal stage, and first prolactin sample concentrations. Sample times after venipuncture and catheter placement: 2, 15 minutes; 3, 30 minutes; 4, 50 minutes.

$* p$-value for difference in change for a given time interval within iron status group.

$* * p$-value for difference in change for a given time interval between iron status groups.

of iron deficiency on the dopamine system in animal studies, we had hypothesized that children who had chronic ID in infancy would show elevated serum prolactin levels 10 y later. The adolescents who had chronic ID in infancy did not show the predicted pattern. Instead, they demonstrated a more prompt decline of serum prolactin shortly after venipuncture, compared with those who had good iron status in infancy.

Dopamine, a central factor in the production, release and reuptake of prolactin, is the primary direct tonic inhibitor of prolactin secretion $(9,10)$. Of three major hypothalamic neuronal populations, tuberoinfundibular dopminergic neurons (TIDA) are considered the primary source of dopamine for inhibiting prolactin secretion (10). Iron deficiency early in life in rats has been shown to alter striatal dopamine regulation, $(13,14)$ but the TIDA system has not been directly studied in the context of iron deficiency. The hypothalamic-TIDA dopamine system is thought to differ from dopaminergic systems in other brain areas and there are species-specific differences (10). However, increased serum prolactin levels and liver prolactin-binding sites have been observed in iron deficient rats $(16,17)$.

The potential biologic mechanisms that underlie our findings of altered prolactin regulation years after a period of chronic iron deficiency are unknown and must be considered cautiously. If early life iron deficiency affected the TIDA dopamine system, one might expect decreased dopaminergic inhibition and higher prolactin levels while iron deficient. Although we did not demonstrate this in infancy, (7) recent findings that infants of anemic mothers with or without malnutrition had elevated cord blood prolactin levels provides support for this mechanism early in life (29). In the present study, we observed an altered serum prolactin pattern in response to stressor more than $10 \mathrm{y}$ after ID in infancy. The pattern is consistent with a swifter response of dopaminergic inhibition. Decreased DAT number or function, as recently observed in the striatal system of iron-deficient rats, could allow extracellular dopamine to accumulate and inhibit prolactin release (14). In addition, chronically high prolactin levels in infancy might lead to fundamental alterations that increased the number of TIDA neurons, with a corresponding increase in prolactin inhibition over time (30). Alterations in other aspects of prolactin regulation are also possible, (e.g., serotonin) (31).

Recent research indicates that early life experiences can result in fundamental neurobiologic changes. The development of CNS regulatory mechanisms for prolactin has been demonstrated to be dynamic, (32-34) and in one rodent study, early postnatal enrichment of maternal care (handling) was associated with lowered serum prolactin response to fearful situations later in life (35). Studies in humans with mental health conditions, such as bipolar disorder and bullemia nervosa, have noted blunted prolactin responses after pharmacologic challenge and serum prolactin responses correlated with the degree of early life trauma. In these conditions, altered serotonin biology was proposed as the indirect mechanism leading to altered dopamine and serum prolactin levels $(31,36)$. Investigations of other neurohormonal systems are also relevant. Rodent studies of the developing hypothalamicpituitary-adrenal axis and the pattern of corticosterone response to stress have shown that the timing and duration of early stressful experiences affects the direction of the stressresponse system long-term, resulting in exaggerated or blunted corticosterone response patterns $(37,38)$.

There were limitations in evaluating serum prolactin responses in the children in this study. In infancy, serum prolactin levels did not differ significantly by sex or age (7). However, as these children entered adolescence, sex and pubertal stage became important factors as observed by others $(5,39)$. We statistically controlled for propensity score (which included sex) and pubertal status, but a stronger design would be to assess children with more equal distribution by group for sex and pubertal status. Another important limitation in this study was that the venipuncture (the stressor of interest) and the first serum sample occurred simultaneously. Both groups showed declining prolactin concentrations thereafter indicating that the peak response in these young adolescents may have occurred in anticipation of, and during the venipuncture, in contrast to the initial rise post-venipuncture observed in adults. It is possible that the chronic ID group subjects had more anticipatory distress that resulted in a peak serum prolactin response even earlier than the good iron status comparison group. An earlier peak before catheter placement could explain the differences in decline of serum prolactin over time. In addition, it is important to recall that more of the chronic ID group adolescents had been rated as wary and hesitant during developmental testing in infancy. This raises the possibility of enduring behavioral differences that might underlie the difference in serum prolactin response. Future studies could explore this further by a repeated sampling approach with a stress after reaching baseline prolactin levels and behavioral measures. Finally, other factors such as dietary tryptophan intake were not monitored in these children and might have affected serum prolactin levels (40).

In summary, serum prolactin levels have not previously been assessed years after a period of iron deficiency in infancy. Our results show an altered serum prolactin response pattern in adolescents who had chronic ID in infancy. We suggest this finding reflects fundamental alterations in the 
regulation of serum prolactin due to effects of early iron deficiency on the dopamine system.

\section{REFERENCES}

1. Ben-Jonathon N, Mershon JL, Allen DL, Steinmetz RW 1996 Extrapituitary prolactin: distribution, regulation, functions, and clinical aspects. Endocr Rev 17:639669

2. Bole-Feysot C, Goffin V, Edery M, Binart N, Kelly P 1998 Prolactin (PRL) and its receptor: actions, signal transduction pathways and phenotypes observed in PRL receptor knockout mice. Endocr Rev 19:225-268

3. Chikanza IC 1999 Prolactin and neuroimmunomodulation: in vitro and in vivo observations. Ann N Y Acad Sci 876:119-130

4. Biondi M, Peronti M, Pacitti F, Pancheri P, Pacifici R, Altieri I, Paris L, Zuccaro P 1994 Personality, endocrine and immune changes after eight months in healthy individuals under normal daily stress. Psychother Psychosom 62:176-184

5. Gerra G, Zaimovic A, Giucastro G, Folli F, Maestri D, Tessoni A, Avanzini P, Caccavari R, Bernasconi S, Brambilla F 1998 Neurotransmitter-hormonal responses to psychological stress in peripubertal subjects: relationship to aggressive behavior. Life Sci 62:617-625

6. Lindh A, Carlstrom K, Eklund J, Wilking N 1992 Serum steroids and prolactin during and after major surgical trauma. Acta Anaesthesiol Scand 36:119-124

7. Lozoff B, Felt BT, Nelson EC, Wolf AW, Meltzer HW, Jimenez E 1995 Serum prolactin levels and behavior in infants. Biol Psychiatry 37:4-12

8. Sobrinho LG 1998 Emotional aspects of hyperprolactinemia. Psychother Psychosom 67:133-139

9. Benker G, Jaspers C, Hausler G, Reinwein D 1990 Control of prolactin secretion. Klin Wochenschr 68:1157-1167

10. Ben-Jonathan N, Hnasko R 2001 Dopamine as a prolactin (PRL) inhibitor. Endocr Rev 22:724-763

11. Albinsson A, Palazidou E, Stephenson J, Andersson G 1994 Involvement of the 5 -HT2 receptor in the 5-HT receptor-mediated stimulation of prolactin release. Eur J Pharmacol 251:157-161

12. deMaeyer E, Adiels-Tegman M 1985 The prevalence of anaemia in the world. World Health Stat Q 38:302-316

13. Beard JL, Connor JR 2003 Iron status and neural functioning. Annu Rev Nutr 23:41-58

14. Lozoff B, Beard J, Connor J, Felt B, Georgieff M, Schallert T 2006 Long-lasting neural and behavioral effects of iron deficiency in infancy. Nutr Rev 64:S34-S43

15. Youdim MB 1985 Brain iron metabolism biochemical and behavioral aspects in relation to dopaminergic neurotransmission. In: Lagoth A (eds) Handbook of Neurochemistry. Plenum Press, New York, pp 731-755

16. Barkey RJ, Ben-Shachar D, Amit T, Youdim MB 1985 Increased hepatic and reduced prostatic prolactin (PRL) binding in iron deficiency and during neuroleptic treatment: correlation with changes in serum PRL and testosterone. Eur J Pharmacol 109:193-200

17. Barkey RJ, Amit T, Ben-Shachar D, Youdim MB 1986 Characterization of the hepatic prolactin receptors induced by chronic iron deficiency and neuroleptics. Eur J Pharmacol 122:259-267

18. Lozoff B, Brittenham GM, Wolf AW, McClish DK, Kuhnert PM, Jimenez E, Jimenez R, Mora LA, Gomez I, Krauskopf D 1987 Iron deficiency anemia and iron therapy: effects on infant developmental test performance. Pediatrics 79:981-995

19. Felt BT, Beard JL, Schallert T, Shao J, Aldridge JW, Connor JR, Georgieff MK, Lozoff B 2006 Persistent neurochemical and behavioral abnormalities in adulthood despite early iron supplementation for perinatal iron deficiency anemia in rats. Behav Brain Res 171:261-270
20. Lozoff B, Jimenez E, Wolf AW 1991 Long-term developmental outcome of infants with iron deficiency. N Engl J Med 325:687-694

21. Lozoff B, Jimenez E, Hagen J, Mollen E, Wolf AW 2000 Poorer behavioral and developmental outcome more than 10 years after treatment for iron deficiency in infancy. Pediatrics 105:E51-

22. Patterson JC, Marrack D, Wiggins HS 1953 The diurnal variation of the serum iron level in erythropoietic disorders. J Clin Pathol 6:105-109

23. Sassin JF, Frantz AG, Weitzman ED, Kapen S 1972 Human prolactin: 24 hour pattern with increase release during sleep. Science 177:1205-1207

24. Richter SD, Schurmeyer TH, Schedlowski M, Hadicke A, Tewes U, Schmidt RE, Wagner TO 1996 Time kinetics of the endocrine response to acute psychological stress. J Clin Endocrinol Metab 81:1956-1960

25. Tanner JM 1962 Growth at Adolescence. Blackwell Scientific, Oxford

26. D'Agostino RBJr 1998 Propensity score methods for bias reduction in the comparison of a treatment to a non-randomized control group. Stat Med 17:2265-2281.

27. Wilder J 1957 The law of initial value in neurology and psychiatry: Facts and problems. J Nerv Ment Dis 125:73-86

28. Littell RC, Milliken GA, Stroup WW, Wolfinger RD 1996 SAS System for Mixed Models. SAS Institute, Cary

29. Mahajan SD, Singh S, Shah P, Gupta N, Kochupillai N 2004 Effect of maternal malnutrition and anemia on the endocrine regulation of fetal growth. Endocr Res 30:189-203

30. Phelps CJ 1994 Pituitary hormones as neurotrophic signals: anomalous hypophysiotrophic neuron differentiation in hypopituitary dwarf mice. Proc Soc Exp Biol Med 206:6-23

31. Steiger H, Gauvin L, Israel M, Koerner N, Ng Ying Kin NM, Paris J, Young SN 2001 Association of serotonin and cortisol indices with childhood abuse in bulimia nervosa. Arch Gen Psychiatry 58:837-843

32. Freemark M, Nagano M, Edery M, Kelly P 1995 Prolactin receptor gene expression in the fetal rat. J Endocrinol 144:285-292

33. Freemark M, Driscoll P, Andrews J, Kelly P, Royster M 1996 Ontogenesis of prolactin receptor gene expression in the rat olfactory system: potential roles for lactogenic hormones in olfactory development. Endocrinology 137:934-942

34. Shah GV, Shyr SW, Grosvenor CE, Crowley WR 1988 Hyperprolactinenmia afte neonatal prolactin (PRL) deficiency in rats: evidence for altered anterior pituitary regulation of PRL secretion. Endocrinology 122:1883-1889

35. Rots NY, deJong J, Workel JO, Levine S, Cools AR, deKloet R 1996 Neonatal maternally deprived rats have as adults elevated basal pituitary-adrenal activity and enhanced susceptibility to apomorphine. J Neuroendocrinol 8:501-506

36. Rinne T, Westenberg HG, den Boer JA, van den Brink W 2000 Serotonergic blunting to meta-chlorophenylpiperazine (m-CPP) highly correlates with sustained childhood abuse in impulsive and autoaggressive female borderline patients. Biol Psychiatry 47:548-556

37. Plotsky PM, Meaney MJ 1993 Early, postnatal experience alters hypothalamic corticotropin-releasing factor (CRF) mRNA, median eminence CRF content and stress-nduced release in adult rats. Brain Res Mol Brain Res 18:195-200

38. van Oers HJ, de Kloet ER, Levine S 1998 Early vs. late maternal deprivation differentially alters the endocrine and hypothalamic responses to stress. Brain Res Dev Brain Res 111:245-252

39. Waterman GS, Dahl RE, Birmaher B, Ambrosini P, Rabinovich H, Williamson D, Novacenko H, Nelson B, Puig-Antich J, Ryan ND 1994 The 24-hour pattern of prolactin secretion in depressed and normal adolescents. Biol Psychiatry 35:440-445

40. Attenburrow MJ, Williams C, Odontiadis J, Powell J, Van de Ouderaa F, Williams M, Cowen PJ 2003 The effect of a nutritional source of tryptophan on dietinginduced changes in brain 5-HT function. Psychol Med 33:1381-1386 